tunity for a survey of past development in science, all the more striking for being placed near the exhibits of such modern developments as those of the Igranic and Gramophone and other companies. The exhibits included some examples of scientific instruments to illustrate the work of a series of London instrument makers in direct succession from Christopher Cock (seventeenth century) to Elliott (nineteenth century), contributed by Mr. 'T. H. Court, among which may be noted Robert Hooke's own microscope; photographs of the original apparatus used by Alessandro Volta in his researches of 1763-1819, exhibited by $\mathrm{Mr}$. Robert W. Paul ; and some early and primitive timemeasuring devices contributed by the Science Museum, from early Egyptian water clocks to a seventeenthcentury turret clock from St. Giles' Church, Cambridge.

The discourses once more attracted keenly interested audiences, whose appreciation was obvious. That on the first evening was delivered by Prof. F. Lloyd Hopwood, whose subject was "Experiments with High Frequency Sound Waves." He made use of a quartz piezo-electric oscillator, the crystals being cut in the form of circular dises with their plane faces parallel to the optical axis and at right angles to an electric or binary axis. This method of producing vibrations is due to Prof. Langevin, of Paris, and many practical applications of it have been made both in peace and war. The quartz discs were immersed in transformer oil contained in glass tanks, suitable arrangements being made for producing both horizontal and vertical beams of sound. The method used in connexion with a horizontal beam was due to Prof. R. W. Boyle, and exemplified stationary waves fobtained by reflection and rendered visible by the striæ formed in dust lying on a horizontal sheet of glass in the path of the beam), interference patterns, defraction effects ; attenuation (observed by bringing into action the frictional dissipation of energy due to the viscosity of the oil vibrating in a confined space, achieved quite simply by supporting a second glass plate almost in contact with the fir s; pressure of sound radiation, shown by means o Langevin's acoustic radiometer. Some biological effects brought about by the agency of ultra-sonic sound waves were then described and illustrated by means of slidesa beautiful example being the segregating of the chloroplasts in the fresh-water plant Nitella. By making use of a vertical beam of ultra-sonic waves some experiments were shown illustrating phenomena not usually associated with sound. These depend on the effect of pressure due to radiation on the surface of oil, which is strikingly shown by the formation of a mound of oil which erupts drops like a miniature volcano. By plunging vessels of appropriate form into this mound, vibrations of great intensity are communicated to the walls of the vessel, or through the walls to liquids contained in them. By these means it is possible to show cavitation in water; the vaporisation of benzene; transverse vibrations of a solid by the pattern -produced in a test tube dusted with lycopodium powder; and the calorific effect by melting a wax ball, which can be made to simulate the descent of a time ball.

On the second evening, Mr. Conrad Beck discoursed on "Lenses." The Greeks, he said, at least as early as 430 B.c., learnt that a piece of glass with curved surfaces could be used as a burning glass, and the derivation of the word 'focus' is from the word meaning 'altar' or place of fire. Text-books treat the focus as a geometric point formed by light entering the lens as a parallel beam. This is incorrect and leads to misconception. The focus of the ancients was a finite spot and not a point. Mr. Beck said that the way to understand the action of a lens is to study how it produces an image, for which three processes are necessary : the production of an image of a spot in the centre of the object on the axis ; the direction of the axial rays from spots on the object away from the axis ; and the examination of a complete bundle of rays from the marginal spot on the object. The Gallilean field glass, telescopes, periscopes, photographic and projecting lenses were discussed, and the study of the Gauss theory for the invention of new and original types of instruments was advocated. Mr. Beck considers that great attention should be paid to the more elementary principles of image formation before the questions of the correction of aberrations or the considerations of diffraction are investigated.

The lecture on the third evening, entitled "Some Colour Problems in Photo-Engraving," was given by Mr. A. J. Bull, and dealt with the effects in threecolour printing of errors in the selective absorption of the three-colour 'filters' and printing inks. Experiments were shown in which white light was imitated by superposing the colours transmitted by threecolour 'filters,' and it was shown that to obtain a white a larger area of blue filter is required than green, and a larger area of green filter than red-blue, green, red being the order of their increasing transparency. The colours obtainable are, however, fairly pure and close to theoretical requirements, so that screen plate processes give colour photographs which are fairly accurate as to colour but much lower in tone. This was shown by examples with the Lumière Autochrome plate. The ideal double colours which are desirable for the purposes of printing were shown by optical superposition of red and green images to obtain a yellow printing colour, green and blue images to obtain a 'blue' printing colour, and blue and red images to obtain a magenta or ' red' printing colour. These were contrasted with the colours of inks actually obtainable and the inaccuracies introduced were shown. These take the form of darkening blues and greens and a loss of reflected blue light with purples and pinks. The methods used for retouching were indicated; in half-tone work the skill of the colour etchers is such that excellent colour prints can be obtained by them from monochrome originals. KathleEN E. Bingham.

\title{
Annual Conference of the Geographical Association.
}

' HE annual conference of the Geographical Associa1 tion was held at the London School of Economics on Jan. 3-5. In addition to the usual business meetings, and some discussions on special problems of the teaching of geography, there were public lectures on some recent research work; and the chief part of the presidential address was also concerned with geographical investigation. The president, Sir H. G. Lyons, gave a concise review of the year's activities and then indicated the vast mass of material now available for geographical study in the reports and maps of the many national and other surveys now at work, and some of the difficulties of access to this material. He suggested that the Association should seek the co-operation of other interested societies in attempts to obtain some satisfactory classification of, and readier access to, this material.

Of the four main papers, ${ }^{1}$ three dealt with human

1 Geomorphological Problems of the Fastern Alps, by Prof. J. Sölch. Natural Environment related to Fuman Activity in the Corn Belt of North America, by Dr. P. W. Bryan. The Balance of Urban and Rural Populations, by Prof. C. B. Fawcett. On Linguistic Frontiers in the
Borderlands of German Speech, by Dr. Vaughan Cornish. 
geography and only one with a purely physical problem. This is a reversal of the proportions which held good in most geographical work even a few years ago ; and it marks the extent to which geographers are now attempting to investigate their central problem of the relations of man to his environment and his modifications of the natural environment. Dr. Bryan gave a vivid account of the cultural landscape of rural central Illinois as it is to-day, after more than half a century's work by a population of skilled agriculturists, under favourable physical, political, and economic conditions, has made that area the heart of the Corn Belt. Here the first settlers, coming from the wooded regions of Western Europe or the Eastern States, chose the forested bottom lands as the most fertile and left the treeless prairie untouched; though their choice was also influenced by the fact that they were dependent on the rivers for bulk transport in the prerailway period. But the soils of the open prairies, fertilised by the humus accumulated from the annual sod of many centuries and retaining their fertility better than the soils of steeper slopes and wetter bottoms, where also tree growth gave a less quantity of humus, are better than any of the other soils except annually renewed river alluvium; and so the prairies are now the richer farmland. The corn belt is by no means a one-crop area, like so much of the cotton belt and some newer parts of the wheat region to the north-west. The corn (maize) is usually grown for two years of a four-year rotation on the best soils and one year in three on other soils. The specialisation of farms in the use of the corn for sale as grain, or for feeding dairy or beef cattle, or swine, is determined mainly by the relative transport facilities for the more or less rapid disposal of their produce by rail to the cities.

A contrast to this account of a modern adjustment to a particular type of environment was furnished by Dr. Cornish's study of the borders of German speech. The author's thesis was that these borders were, for the most part, fixed at the time when Christianity was adopted by, or imposed on, the several peoples concerned; that the Church estimated carefully, and usually accurately, the territorial limits of the languages in use by its converts, and adapted its organisation of bishoprics and archiepiscopal provinces to those limits; and further, that through this organisation the Church did much to stabilise the boundaries which it had adopted and the languages which it recognised and helped to develop. Thus, on the whole, the boundaries established from the fifth century (in the west) to the thirteenth century (in the north-east) remain to-day. The thesis was illustrated by detailed studies of the linguistic borders in Belgium, Alsace-Lorraine, Switzerland, Tirol, Carinthia, Bohemia, Poland, and Slesvig.

The third paper, by Prof. C. B. Fawcett, was an examination of a particular problem of the distribution of population. The differences of classification in various censuses make it impossible to obtain close and trustworthy comparisons of the proportions of urban and rural populations in many countries. According to such census returns, the urban population ranges from 10 per cent of the total in India to 79 per cent in England, and from 3 per cent in Assam to more than 90 per cent in the southern states of New England. Such numerical comparisons are only possible for part of the last century and for the more advanced countries. The maximum numbers of the urban population are fixed by the surplus food produced by the rural population, in any self-contained region and in the world as a whole, and the possibility of transporting that food to the towns. As a result of the improvement of the tools and technique of agriculture, and of transport, during the last two centuries the urban population is now more than half of the total in most of the lands of western civilisation. These improvements act in two ways, first by reducing the number of workers required to cultivate a given quantity of any crop, and second by enabling almost all the industries other than agriculture to be concentrated in the towns. A study of the numbers of the agricultural workers and the proportions of homegrown foods in Great Britain led to the estimate that under the conditions of this country the rural population, not including therein urban workers resident in rural districts, should number at least 25 per cent of the whole population to make the country selfsupporting in regard to its principal foodstuffs.

Prof. Sölch's lecture was accompanied by a number of magnificent photographs of Alpine scenery illustrating the existence of several comparatively plane, though much dissected, surfaces, which he termed 'flats,' at various altitudes in the Alps. He compared these with similar land forms in the British highlands, and appealed for comparative studies and co-operation in the task of investigating the ages of these 'flats' and their relations to different stages in the uplift of the Alps and to glacial and interglacial periods.

These papers will probably be published in full in early numbers of Geography, the magazine of the Geographical Association, which is to be issued as a. quarterly from now on.

\section{University and Educational Intelligence.}

Applications are invited by the committee of the Royal Society and the University of Sheffield appointed to administer the Sorby Research Fund, for the Sorby research fellowship, value $£ 500$ per annum and tenable for five years. Particulars may be obtained from the Assistant Secretary of the Royal Society, Burlington House, London, W.1

IN the recent Report of the National Fuel and Power Committee it was stated that the most economic use of fuels is largely dependent on a highly trained personnel. With this in mind, the Governors of the Sir John Cass Teohnical Institute, Aldgate, E.C.3, are extending their existing courses in fuel technology by an advanced and post-graduate course on "Coal Carbonisation," and the inaugural lecture will be delivered by Dr. F. S. Sinnatt, of the Fuel Research Board, on Jan. 28 at 7 P.M. Admission to this lecture is free.

NEGRo universities and colleges in the United States of America have six times as many students as they had ten years ago. This very striking growth is one of the developments brought to light by a comprehensive survey of 79 institutions for the higher education of negroes recently completed by the United States Bureau of Education. It means that the negro universities and colleges have been growing three times as fast as the others. Their aggregate annual income increased in the same period nearly fourfold. Even now, however, their students constitute only onesixtieth of the total number of university and college students in the United States, and their incomes amount to only one-fiftieth of the aggregate incomes of all such institutions. Although there has been a correspondingly rapid increase in the number of negroes entering the professions for which preparation can be had only in institutions for higher education, the number of negro doctors, dentists, architects, engineers, etc., is still wholly insufficient to provide all the professional service required by the negro population. 